\title{
Article \\ Epidemiological Characterization and the Impact of Healthcare-Associated Pneumonia in Patients Admitted in a Northern Portuguese Hospital
}

\author{
Lucía Méndez $^{1,2, *}$, Pedro Castro ${ }^{3}$, Jorge Ferreira ${ }^{1}$ and Cátia Caneiras ${ }^{2,4,5}$ (D) \\ 1 Pneumology Department, Centro Hospitalar de Entre Douro e Vouga, \\ 4520-221 Santa Maria da Feira, Portugal; jorge.ferreira@chedv.min-saude.pt \\ 2 EnviHealthMicro Lab, Microbiology Research Laboratory on Environmental Health, Institute of \\ Environmental Health (ISAMB), Faculty of Medicine, Universidade de Lisboa, 1649-028 Lisboa, Portugal; \\ ccaneiras@medicina.ulisboa.pt \\ 3 Intensive Care Unit, Centro Hospitalar de Entre Douro e Vouga, 4520-221 Santa Maria da Feira, Portugal; \\ pedro.castro@chedv.min-saude.pt \\ 4 Institute of Preventive Medicine and Public Health, Faculty of Medicine, Universidade de Lisboa, \\ 1649-028 Lisboa, Portugal \\ 5 Microbiology and Immunology Department, Faculty of Pharmacy, Universidade de Lisboa, \\ 1649-003 Lisboa, Portugal \\ * Correspondence: lucia.gonzalez@chedv.min-saude.pt
}

Citation: Méndez, L.; Castro, P.;

Ferreira, J.; Caneiras, C.

Epidemiological Characterization and the Impact of Healthcare-Associated Pneumonia in Patients Admitted in a Northern Portuguese Hospital. J. Clin Med. 2021, 10, 5593. https://doi.org/ $10.3390 / \mathrm{jcm} 10235593$

Academic Editor: Satoru Ebihara

Received: 13 October 2021

Accepted: 27 November 2021

Published: 28 November 2021

Publisher's Note: MDPI stays neutral with regard to jurisdictional claims in published maps and institutional affiliations.

Copyright: (c) 2021 by the authors. Licensee MDPI, Basel, Switzerland. This article is an open access article distributed under the terms and conditions of the Creative Commons Attribution (CC BY) license (https:/ / creativecommons.org/licenses/by/ $4.0 /)$.

\begin{abstract}
Pneumonia is one of the main causes of hospitalization and mortality. It's the fourth leading cause of death worldwide. Healthcare-associated infections are the most frequent complication of healthcare and affect hundreds of millions of patients around the world, although the actual number of patients affected is unknown due to the difficulty of reliable data. The main goal of this manuscript is to describe the epidemiological characteristics of patients admitted with pneumonia and the impact of healthcare-associated pneumonia (HCAP) in those patients. It is a quantitative descriptive study with retrospective analysis of the clinical processes of 2436 individuals for 1 year (2018) with the diagnosis of pneumonia. The individuals with $\leq 5$ years old represented $10.4 \%(n=253)$ and $\geq 65$ were $72.6 \%(n=1769)$. 369 cases resulted in death, which gives a sample lethality rate of $15.2 \%$. The severity and mortality index were not sensitive to the death event. We found $30.2 \%(n=735)$ individuals with HCAP and $0.41 \%(n=59)$ with ventilator-associated pneumonia (VAP). In only 59 individuals $(2.4 \%)$ the agent causing pneumonia was isolated. The high fatality rate obtained shows that pneumonia is a major cause of death in vulnerable populations. Moreover, HCAP is one of the main causes of hospital admissions from pneumonia and death and the most pneumonias are treated empirically. Knowledge of the epidemiology characterization of pneumonia, especially associated with healthcare, is essential to increase the skills of health professionals for the prevention and efficient treatment of pneumonia.
\end{abstract}

Keywords: pneumonia; healthcare-associated pneumonia; epidemiology; hospitalization; Klebsiella pneumoniae; gram-negative; Portugal

\section{Introduction}

Pneumonia, along with other lower respiratory tract infections, is the fourth leading cause of death worldwide, accounting for over 4 million deaths per year [1,2]. At the European Union, pneumonia remains the most frequent cause of death from infection, especially in the elderly [3]. In Portugal, pneumonia is one of the main causes of hospitalization and mortality. In 2018, about 40,345 patients were hospitalized with the diagnosis of pneumonia and the associated mortality rate was $20.3 \%$ [4].

Nosocomial infections are infections acquired by a patient during healthcare that did not have it or was not incubating it at the time of admission [5]. They constitute the most 
frequent complication of health care, but the actual number of patients affected is unknown due to the difficulty of reliable data [6]. These infections increase hospital stay, dysfunctions and promote greater resistance of microorganisms to antimicrobials. Healthcare-associated pneumonia (HCAP) includes any patient who was hospitalized in an acute care hospital for two or more days within 90 days of infection; resided in a nursing home or long-term care facility; received recent intravenous antibiotic therapy, chemotherapy, or wound care within the past 30 days of the current infection; attended a hospital or hemodialysis clinic; or lives with a family member infected with a multidrug resistant organism $[7,8]$. Within HCAP we find the pneumonia acquired by the Hospital (HAP) and the pneumonia associated with the respirator (VAP). HAP is a pneumonia that occurs $48 \mathrm{~h}$ or more after admission which was not incubating at the time of admission [7-9]. The definition of VAP is a type of pneumonia acquired in hospitals that occurs more than $48 \mathrm{~h}$ after endotracheal intubation. It can be more precisely classified as early onset (until the first $96 \mathrm{~h}$ of mechanical ventilation and late onset (more than $96 \mathrm{~h}$ after initiation of mechanical ventilation $[8,9]$.

In Portugal, the epidemiological and clinical evidence available is focused on communityacquired pneumonia (CAP) [10-17] at global and regional level in mainland Portugal [18], on CAP and influenza hospitalizations [11,19] and, recently on organizing pneumonia due to COVID-19 [20-22]. No studies have focused specifically on HCAP. In fact, epidemiological data to characterize HCAP are scarce and difficult to obtain, despite the relevance for the scientific knowledge and for prevention and therapeutic optimizing of HCAP. The purpose of this manuscript is to describe the epidemiological characteristics of patients admitted with pneumonia and to evaluate the impact of HCAP within the universe of patients admitted with pneumonia.

\section{Materials and Methods}

This manuscript describes a descriptive and quantitative study of all individuals hospitalised for pneumonia in a secondary care hospital in northern Portugal during 2018. All individuals admitted to the hospital from 1 January 2018 to 31 December 2018, with the diagnosis of pneumonia, were included. All hospital admission wards were considered. Epidemiological and clinical variables were analysed, namely: age, gender, pathogenic agent isolated, nosocomial pneumonia, severity index and mortality.

The individuals included in the sample were classified as pneumonia, according to the Homogeneous Diagnostic Groups (HDG), according to the All Patient Refined DRGs (APR-DRG) which is a classification system for patients admitted to acute hospitals that incorporate severity of illness. In order to make this grouping, the International Classification of Diseases 9th Clinical Modification of Review (CIE-9-CM) is used in Portugal [23]. Considering the differences in patients with respect to the severity of the disease and the risk of mortality, this diagnostic grouping allows subdivision into subclasses according to these factors. The severity of the disease is understood as an extension of physiological decompensation or loss of organic function and is subclassified as 4 (1: Minor, 2: Moderate, 3: Major and 4: Extreme). The risk of mortality is understood as the patient's probability of death and is subdivided into 4 subclasses (1: Minor, 2: Moderate, 3: Major and 4: Extreme) [24,25].

The classification of the HCAP used was based on the Consensus Document on Nosocomial Pneumonia [5]. The guarantee of confidentiality of the information and the anonymity of the participants was a concern in this study, so that in the data collection and analysis process, there was no element that could identify the individuals in the sample. The study was conducted according to the guidelines of the Declaration of Helsinki, and approved by the Ethics Committee of Centro Hospitalar de Entre Douro e Vouga (protocol code CA-102/2020-0t_MP/AC, 24 April 2020). 


\section{Results}

Between 1 January 2018 and 31 December 2018 were hospitalized 17,176 individuals. Of these, were admitted with the diagnosis of pneumonia 2436 individuals, representing $14.18 \%$ of the total number of individuals admitted in that year.

\subsection{Epidemiological Characterization}

The occurrence of the episodes were more frequent during the coldest months with a total of $61.78 \%$ (Autumn: $19.58 \%, n=477$ ) and Winter: $42.20 \%, n=1028$ ) than during the more temperate months $38.21 \%$ (Spring: $21.84 \%, n=532$ ) and Summer: $16.38 \%, n=399$ ). In the sample we found $51.8 \%(n=1262)$ men and the mean age was $68.8 \pm 27.6$ years and median 79 years. Of these $11.9 \%(n=292)$ were children of whom $10.38 \%(n=253)$ were 5 years old or younger. For individuals over 65 years of age, this corresponds to $72.62 \%$ $(n=1769)$ of the sample.

The average length of stay was $10.1 \pm 7.2$ days, the minimum length of stay was 1 day and the maximum length was 81 days. Of the individuals studied 369 resulted in death, which gives a lethality rate of $15.15 \%$ (CI 95\%; 13.59-16.67). Among the dead individuals we found $0.04 \%$ (CI 95\%; 195.72-195.80) $(n=1)<5$ years and $11.08 \%$ (CI 95\%; 87.99-111.81) $(n=270)>65$ years which detailed frequency is presented at Figure 1 . The individuals were classified acco-rding to the severity and mortality risk index, following the criteria of the Diagnosis Related Groups (DRG) [25] as it is shown in Table 1.

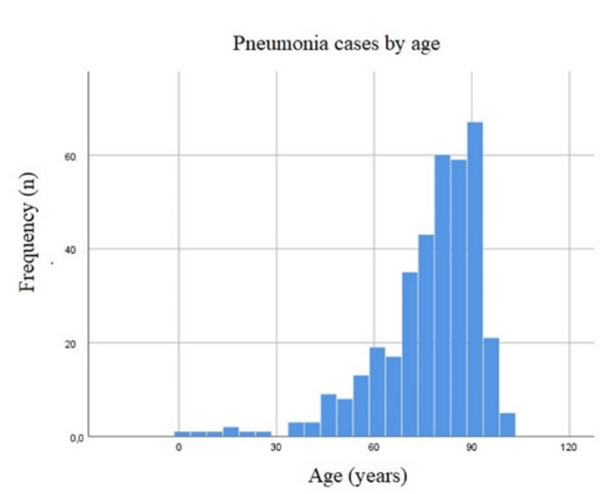

(a)

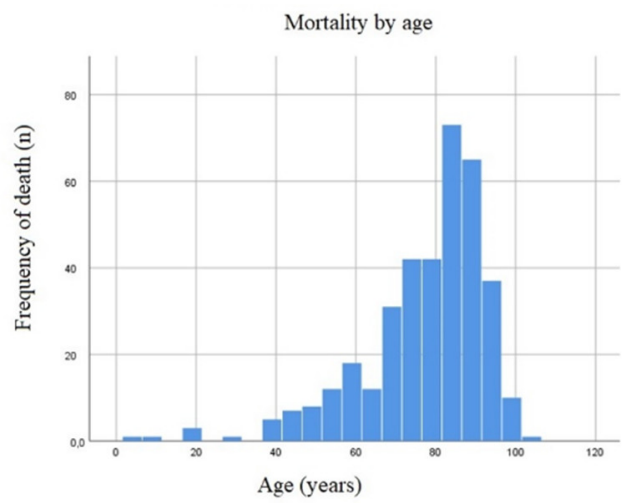

(b)

Figure 1. Number of cases of pneumonia (a) and mortality (b) frequency distributed by age.

Table 1. Classification according to the severity and mortality rates that follows the DRG criteria [25].

\begin{tabular}{ccccc}
\hline Index & Severity $(\boldsymbol{n})$ & $\mathbf{\%}$ & Mortality Risk $(\boldsymbol{n})$ & $\mathbf{\%}$ \\
\hline 1 & 286 & 11,74 & 445 & 18.27 \\
2 & 530 & 21.76 & 386 & 15.85 \\
3 & 1363 & 55.92 & 1092 & 44.83 \\
4 & 252 & 10.34 & 508 & 20.85 \\
Unclassified & 5 & 0.21 & 5 & 0.21 \\
\hline
\end{tabular}

To determine the degree of specificity and sensitivity of the severity and mortality rates in relation to death prediction, the Receiver Operating Characteristic curves (ROC curves) were performed and analyzed, as can be seen in Figure 2. 


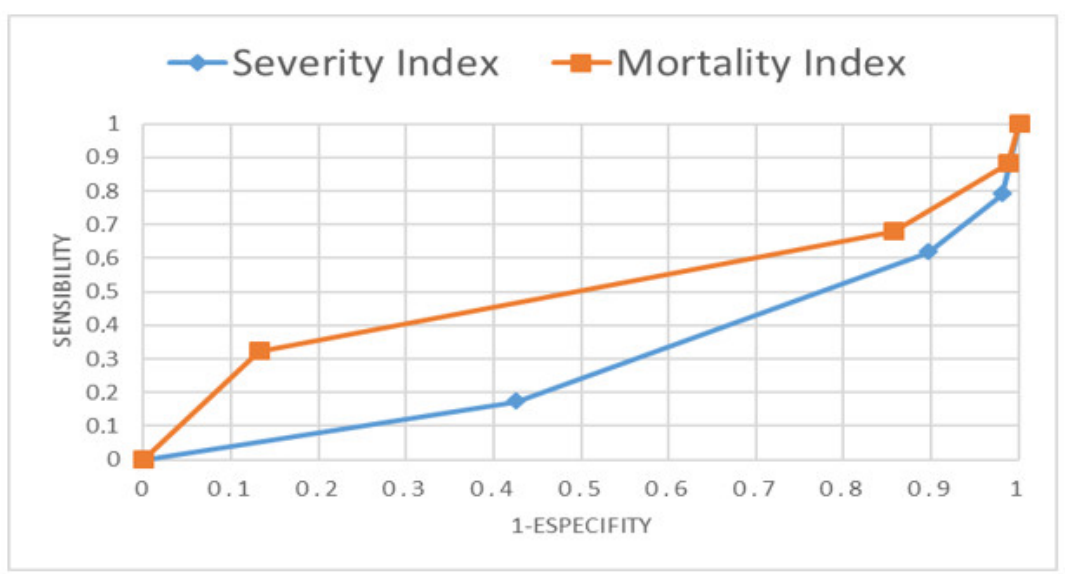

Figure 2. ROC curves of the severity and mortality index as a predictive factor for the occurrence of death.

\subsection{Microbiological and HCAP Characterization}

At only 59 of the individuals the agents causing pneumonia were isolated, which constitutes $2.42 \%$ of the total sample. At $39.28 \%(n=22)$ of these isolations the Gramnegative pathogen Klebsiella pneumoniae was identified (Figure 3). Pseudomonas aeruginosa $(n=8)$ was the second most frequently isolated microorganism.

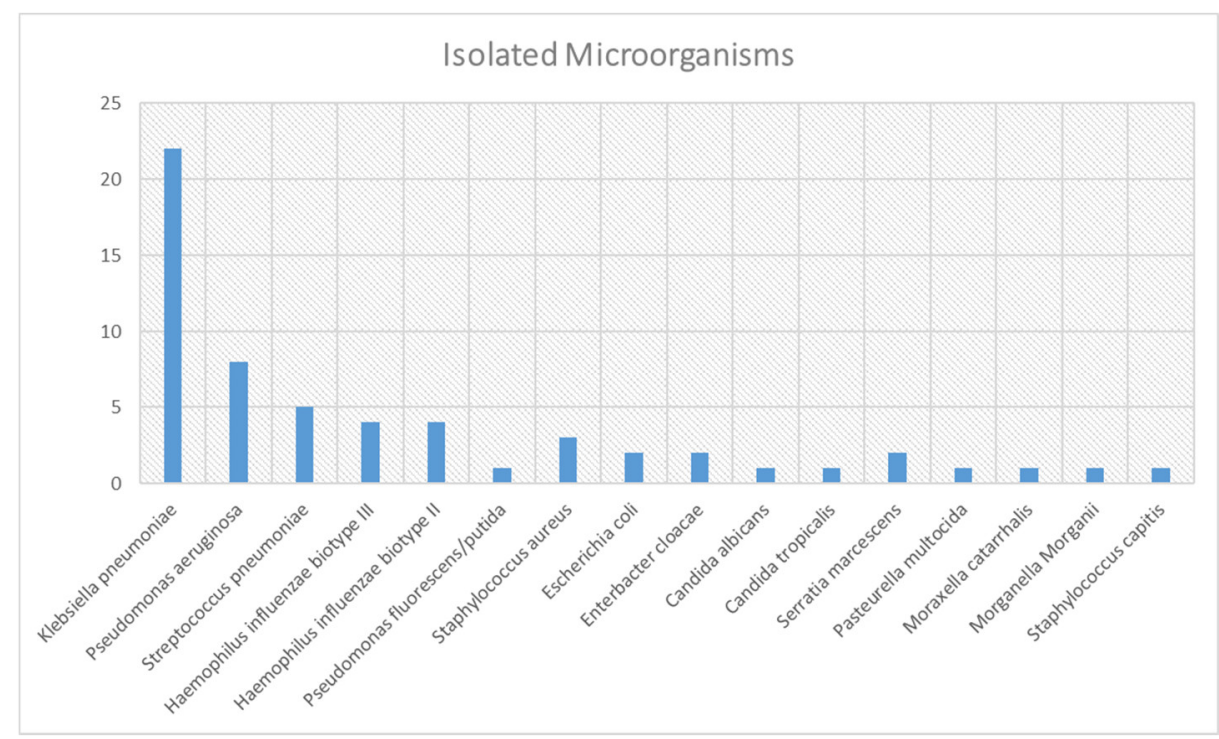

Figure 3. Identification of the microorganisms isolated in respiratory samples.

Considering the 2436 individuals studied with pneumonia, 30.17\% $(n=735)$ of their pneumonia were associated with health care. Within these individuals, it was found that in $0.41 \%(n=10)$ the pneumonia was associated with mechanical ventilation (VAP) and in $7.92 \%(n=193)$ of the cases the pneumonic episode started during the current hospitalization (HAP). Data is shown in Figure 4. Of the 735 individuals with HCAP, 153 died, which is $6.28 \%$ of mortality considering all patients with pneumonia, $20.82 \%$ of mortality considering the HCAP classification and $41.46 \%$ of the total of deaths at hospital at the same period. 


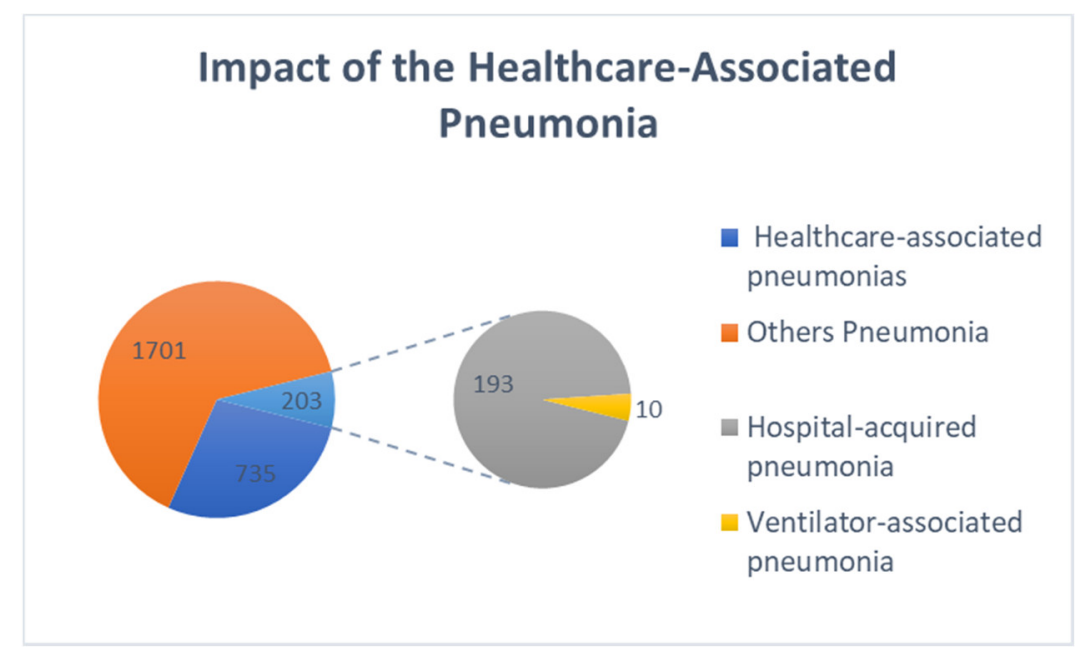

Figure 4. Impact of Healthcare-Associated Pneumonia. This figure represents the number of individuals with HCAP, HAP and VAP, in relation to the total number of individuals admitted for pneumonia.

Mortality was also analysed for each of the different types of nosocomial pneumonia and related to gender. Of the total number of individuals affected by VAP $0.69 \%(n=7)$ in relation to the total sample died, being $0.16 \%(n=4)$ males and $0.12 \%(n=3)$ females. In relation to individuals with HAP, there were $1.72 \%(n=42)$, being $0.78 \%(n=19)$ males and $0.94 \%(n=23)$ females. The rest of the nosocomial pneumonias fell under HCAP and we found that $6.28 \%(n=153)$ died during hospitalisation, with $2.91 \%(n=71)$ being male and $3.37 \%(n=82)$ being female. These data are shown in Table 2.

Table 2. Classification of the types of nosocomial pneumonia and mortality rate, in total number and discriminated by gender and type of pneumonia considering the total of individuals with pneumonia $(n=2436)$.

\begin{tabular}{ccccc}
\hline Pneumonia & $\begin{array}{c}\text { Individuals } \\
\boldsymbol{n} \mathbf{( \% )}\end{array}$ & Total & $\begin{array}{c}\text { Mortality } \\
\boldsymbol{n} \mathbf{( \% )}\end{array}$ & \\
\hline & & $7(0.29)$ & $4(0.16)$ & Male \\
\hline VAP & $10(0.41)$ & $42(1.72)$ & $19(0.78)$ & $3(0.12)$ \\
HAP & $193(7.92)$ & $104(4.27)$ & $48(1.98)$ & $56(2.30)$ \\
\hline HCAP & $532(21.84)$ & $153(6.28)$ & $71(2.91)$ & $82(3.37)$ \\
\hline
\end{tabular}

\section{Discussion}

The main goal of this study was to characterize the epidemiological and clinical characteristics of the patients admitted with pneumonia at a secondary care hospital in Portugal and to evaluate the impact of HCAP. To the best of authors knowledge, it is the first study focused on HCAP in Portugal.

Pneumonic episodes can occur at any time of the year, they have a greater incidence in the coldest months, especially in winter. The colder air acts as an irritant to the airways, which facilitates the installation and multiplication of infectious agents, and during the colder seasons, people tend to stay longer in closed environments, which favors the propagation of infectious agents among people $[26,27]$. The gender of individuals is not a predisposing factor for pneumonia, affecting both genders equally. The days of hospital admission obtained in our study corresponds to the average number of days of admission by pneumonia in Portugal [28-30]. Of relevance, the most vulnerable population with the highest associated risk of pneumonia is almost the entire sample (over 65 and 5 years old or younger), so being very young or elderly can be a risk factor for pneumonia. Moreover, we demonstrated an age-dependency on the pneumoniae frequency and mortality. 
The health system is fundamental for the success of the treatment and prevention of pneumonia. Moreover, it is essential to ensure access to vaccination for vulnerable populations, as well as to encourage healthy lifestyles, with adequate nutrition and, above all, to encourage breastfeeding in children. The characteristics of our current societies, such as increased environmental pollution and overcrowding, may be aggravating factors for the increase of pneumonic episodes in vulnerable individuals, as well as the increased life expectancy in developed countries [2]. Healthcare-associated pneumonia (HCAP) has been introduced as an entity in the ATS/IDSA guidelines update from 2005 [31] and still is a controversy concept, especially in Europe [32-34] considering the difficulty to identify predictors for such risk [35].

Mortality from pneumonia is improving in most EU countries, however substantial variation in trends remains between countries and Portugal was excluded due to missing data. [36]. The mortality rate obtained in our study $(20.82 \%$ of mortality considering the HCAP classification) is similar to previous studies on CAP mortality $(20.4 \%, 2000-2009)$ [17] and total pneumonia $(20.3 \%, 2018)$ in Portugal [4] but significantly lower when compared to the data reported in $2015(57.7 \%)$ [3]. Some factors that occurred in the last years in Portugal may have helped reduce this rate. In July 2015, the 23-valent pneumococcal polysaccharide (BPPV23) vaccine was included in the National Vaccination Plan $[37,38]$. Coincidentally, in 2013 the priority health program was created: Program for the Prevention and Control of Infections and Antimicrobial Resistance (PPCIRA), which aims to reduce the rate of infection associated with health care and promote the correct use of antimicrobials [39]. This mortality rate was particularly worrying in the elderly population, in line with a national study that have concluded that patients older than 75 years and comorbidities contribute decisively to the risk of dying from pneumonia in the hospital [40].

Nosocomial pneumonias have a major impact on hospital admissions, constituting a significant number in relation to the total number of complicated pneumonias requiring hospital admission, with a high risk of death from pneumonia [6]. This implies high health and human costs for hospitals. The quality and safety of care provided in hospitals must be a priority for national healthcare systems. Worryingly, most pneumonia (>95\%) are treated empirically considering that only in few situations the infectious agent is isolated. At the top of the list of isolations we find Klebsiella pneumoniae, which can indicate that the trend of respiratory isolations has changed in the last years and we can highlight the increase of relevance of Gram-negative microorganisms [41]. However, this results should be interpreted with caution regarding that only $2 \%$ of the clinical situations have a microorganism identified.

Of relevance, pneumonia has represented $>40 \%$ of the total of deaths at the hospital at the same period, highlighting the need to implement more studies on HCAP epidemiology and clinical burden. Previous studies highlighted that room for improvement in antibiotic prescription in Healthcare-Associated Pneumonia currently remains and that new strategies for a better use of the adopted tools and definition of new antimicrobial stewardship initiatives are needed to improve compliance to recommendations [42]. In fact, local guidelines and recommendations to treat common infectious diseases are a cornerstone of most Antimicrobial Stewardship programs [43]. More precise instruments are needed to heighten clinicians' index of suspicion for treating probable resistant pathogens with appropriate empirical antibiotic choices [42]. Furthermore, an effective surveillance system to provide quality data and improve the monitoring and epidemiologic characterization of Healthcare Associated infections should be evaluated and implemented [44-48].

The Portuguese health institutions code patients with the severity and risk of mortality rates. However, at the clinical level they are not good predictive indicators for the event of death. Their use is more relevant for the management teams of healthcare institutions and standard indices such as Pneumonia severity index or CURB 65, which are suggested by guidelines for pneumonia from American Thoracic Society and Infectious Diseases Society of America [49] are not currently used. 
One limitation that this study is the absence of classification of all types of pneumonia that could give us more detailed information about the causes that determine complicated pneumonia that needs hospital admission. Another limitation found is the absence of the antibiotherapy used, which would give us the therapeutic tendency used in the empirical treatment of pneumonia. Overall mortality should be higher in patients who attended a hospital or hemodialysis clinic or received intravenous chemotherapy in the 30 days before pneumonia, and among patients who resided in a nursing home or long-term-care facility [34]. Given the focus on HCAP, information on the Healthcare setting frequented by these patients would be useful, as well as the delay of onset of the HCAP and unfortunately was not available. However, this study provides a robust epidemiological characterization of pneumonia, especially HCAP. To the best authors knowledge this is the first study in Portugal that addressed HCAP epidemiology and clinical burden. Future research is needed to increase knowledge about other types of pneumonia and the relation with causative agents and the treatment used, to better understand the impact that pneumonia on the hospital population.

\section{Conclusions}

This manuscript highlight that pneumonia constitute a high risk of mortality for vulnerable populations and is one of the leading causes of hospital admission. The impact of HCAP alerts us to the critical action of infection prevention and control measures in hospitals and should incentive the increase of scientific studies in this crucial area. Reducing the incidence of pneumonia in general and HCAP in particular, will allow an significative improvement in the quality and safety of patient healthcare.

Author Contributions: Conceptualization, L.M. and C.C.; Formal analysis, L.M. and P.C.; Investigation, L.M. and J.F.; Methodology, L.M.; Supervision, C.C.; Writing-original draft, L.M.; Writingreview \& editing, L.M., P.C., J.F. and C.C. All authors have read and agreed to the published version of the manuscript.

Funding: This research received no external funding.

Institutional Review Board Statement: The study was conducted according to the guidelines of the Declaration of Helsinki, and approved by the Ethics Committee of Centro Hospitalar de Entre Douro e Vouga (protocol code CA-102/2020-0t_MP/AC, 24 April 2020).

Informed Consent Statement: The research has been based on the retrospective analysis of clinical data so the informed consent statement is not required.

Conflicts of Interest: The authors declare no conflict of interest.

\section{References}

1. Nacional Institute of Health and Care Excellence. Pneumonia in adults: Diagnosis and Pneumonia in adults: Diagnosis and management. Published: 3 December 2014. Available online: www.nice.org.uk/guidance/cg191 (accessed on 2 February 2019).

2. Fórum Internacional de Sociedades Respiratórias. O Impacto Global da Doença Respiratória—Segunda Edição—2017. Available online: https:/ / www.who.int/gard/publications/The_Global_Impact_of_Respiratory_Disease_POR.pdf (accessed on 10 March 2019).

3. OECD/European Union. Health at a Glance: Europe 2018: State of Health in the EU Cycle, OECD Publishing, Paris/European Union, Brussels 2018. Available online: https:/ /doi.org/10.1787/health_glance_eur-2018-en (accessed on 12 April 2019).

4. Carvalheira Santos, A. $13^{\circ}$ Relatorio do Observatorio Nacional de Doenas Respiratorias 2016/2017. Available online: https: //www.ondr.pt/files/Relatorio_ONDR_2018.pdf (accessed on 20 April 2019).

5. Froes, F.; Paiva, J.A.; Amaro, P.; Baptista, J.P.; Brum, G.; Bento, H.; Duarte, P.; Dias, C.S.; Gloria, C.; Estrada, H.; et al. Consensus document on nosocomial pneumonia. Rev. Port. Pneumol. 2007, 13, 419-486. [CrossRef]

6. Kyu, H.H.; Abate, D.; Abate, K.H.; Abay, S.M.; Abbafati, C.; Abbasi, N.; Abbastabar, H.; Abd-Allah, F.; Abdela, J.; Abdelalim, A.; et al. Global, regional, and national disability-adjusted life-years (DALYs) for 359 diseases and injuries and healthy life expectancy (HALE) for 195 countries and territories, 1990-2017: A systematic analysis for the Global Burden of Disease Study 2017. Lancet 2018, 392, 1859-1922. [CrossRef]

7. Guimaraes, C.; Lares Santos, C.; Costa, F.; Barata, F. Pneumonia associated with health care versus community acquired pneumonia: Different entities, distinct approaches. Rev. Port. Pneumol. 2011, 17, 168-171. [CrossRef] 
8. Torres, A.; Niederman, M.S.; Chastre, J.; Ewig, S.; Fernandez-Vandellos, P.; Hanberger, H.; Kollef, M.; Li Bassi, G.; Luna, C.M.; Martin-Loeches, I.; et al. International ERS/ESICM/ESCMID/ALAT guidelines for the management of hospital-acquired pneumonia and ventilator-associated pneumonia: Guidelines for the management of hospital-acquired pneumonia (HAP)/ventilatorassociated pneumonia (VAP) of the European Respiratory Society (ERS), European Society of Intensive Care Medicine (ESICM), European Society of Clinical Microbiology and Infectious Diseases (ESCMID) and Asociacion Latinoamericana del Torax (ALAT). Eur. Respir. J. 2017, 50. [CrossRef]

9. Kalil, A.C.; Metersky, M.L.; Klompas, M.; Muscedere, J.; Sweeney, D.A.; Palmer, L.B.; Napolitano, L.M.; O'Grady, N.P.; Bartlett, J.G.; Carratala, J.; et al. Management of Adults with Hospital-acquired and Ventilator-associated Pneumonia: 2016 Clinical Practice Guidelines by the Infectious Diseases Society of America and the American Thoracic Society. Clin. Infect. Dis. 2016, 63, e61-e111. [CrossRef]

10. Antunes, C.; Pereira, M.; Rodrigues, L.; Organista, D.; Cysneiros, A.; Paula, F.; Nunes, B.; Barbosa, P.; Barbara, C.; Escoval, A.; et al. Hospitalization direct cost of adults with community-acquired pneumonia in Portugal from 2000 to 2009. Pulmonology 2020, 26, 264-267. [CrossRef]

11. Dias, J.; Correia, A.M.; Queiros, L. Community-acquired pneumonia and influenza hospitalisations in northern Portugal, 2000-2005. Eurosurveillance 2007, 12, 13-14. [CrossRef] [PubMed]

12. Froes, F. Morbidity and mortality of community-acquired pneumonia in adults in Portugal. Acta Med. Port. 2013, 26, 644-645. [PubMed]

13. Froes, F.; Diniz, A.; Mesquita, M.; Serrado, M.; Nunes, B. Hospital admissions of adults with community-acquired pneumonia in Portugal between 2000 and 2009. Eur. Respir. J. 2013, 41, 1141-1146. [CrossRef]

14. Oliveira, A.G. Current management of hospitalized community acquired pneumonia in Portugal. Consensus statements of an expert panel. Rev. Port. Pneumol. 2005, 11, 243-282.

15. Pessoa, E.; Barbara, C.; Viegas, L.; Costa, A.; Rosa, M.; Nogueira, P. Factors associated with in-hospital mortality from communityacquired pneumonia in Portugal: 2000-2014. BMC Pulm. Med. 2020, 20, 18. [CrossRef]

16. Oliveira, A.G. Current management of hospitalized community acquired pneumonia in Portugal. Consensus statements of an expert panel. Rev. Port. Pneumol. 2006, 12, 211-212, author reply 213.

17. Teixeira-Lopes, F.; Cysneiros, A.; Dias, A.; Durao, V.; Costa, C.; Paula, F.; Serrado, M.; Nunes, B.; Diniz, A.; Froes, F. Intra-hospital mortality for community-acquired pneumonia in mainland Portugal between 2000 and 2009. Pulmonology 2019, 25, 66-70. [CrossRef]

18. Froes, F. Pneumonia in the adult population in continental Portugal-Incidence and mortality in hospitalized patients from 1998 to 2000. Rev. Port. Pneumol. 2003, 9, 187-194. [CrossRef]

19. Rodrigues, E.; Machado, A.; Silva, S.; Nunes, B. Excess pneumonia and influenza hospitalizations associated with influenza epidemics in Portugal from season 1998/1999 to 2014/2015. Influenza Other Respir Viruses 2018, 12, 153-160. [CrossRef]

20. Camoes, J.; Lobato, C.T.; Beires, F.; Gomes, E. Legionella and SARS-CoV-2 Coinfection in a Patient With Pneumonia-An Outbreak in Northern Portugal. Cureus 2021, 13, e12476. [CrossRef] [PubMed]

21. Carvalho, A.; Cunha, R.; Lima, B.A.; Pereira, J.M.; Madureira, A.J. Chest CT imaging features of COVID-19 pneumonia: First radiological insights from Porto, Portugal. Eur. J. Radiol. Open 2020, 7, 100294. [CrossRef] [PubMed]

22. Méndez, L.; Ferreira, J.; Caneiras, C. Hafnia alvei Pneumonia: A Rare Cause of Infection in a Patient with COVID-19. Microorganisms 2021, 9, 2369. [CrossRef]

23. International Classification of Diseases, Ninth Revision (ICD-9) (2015). Centers for Disease Control and Prevention. Available online: https:/ / www.cdc.gov/nchs/icd/icd9.htm (accessed on 3 April 2019).

24. Agrupador de GDH (Grupos de Diagnósticos Homogéneos) All Patient Refined DRG (Diagnosis Related Groups), Circular Normativa No 22/2014/DPS/ACSS (2014). Administração Central dos Sistemas de Saúde. Available online: http:/ / www2.acss. min-saude.pt/Default.aspx?TabId=460\&language=pt-PT (accessed on 10 April 2019).

25. Fetter, R.B. Diagnosis Related Groups: A Product Oriented Approach to Hospital Management, Health Systems Management Group; School of Organization and Management, Yale University: New Haven, CT, USA, 1983.

26. Irizar Aramburu, M.I.; Arrondo Beguiristain, M.A.; Insausti Carretero, M.J.; Mujica Campos, J.; Etxabarri Perez, P.; Ganzarain Gorosabel, R. Epidemiology of community-acquired pneumonia. Aten Primaria 2013, 45, 503-513. [CrossRef]

27. Saynajakangas, P.; Keistinen, T.; Tuuponen, T. Seasonal fluctuations in hospitalisation for pneumonia in Finland. Int. J. Circumpolar Health 2001, 60, 34-40. [CrossRef] [PubMed]

28. Direção-Geral da Saúde. Doenças Respiratórias em Números, 2015 Programa Nacional para as Doenças Respiratórias. 2016. Available online: https://www.dgs.pt/estatisticas-de-saude/estatisticas-de-saude/publicacoes/portugal-doencas-respiratoriasem-numeros-2015- (accessed on 2 May 2019).

29. Instituto Nacional de Estatística Portugal. Available online: https://www.ine.pt/xportal/xmain?xpid=INE\&xpgid=ine_ publicacoes\&PUBLICACOESpub_boui=277095050\&PUBLICACOESmodo=2\&xlang=pt (accessed on 14 May 2019).

30. Menendez, R.; Cremades, M.J.; Martinez-Moragon, E.; Soler, J.J.; Reyes, S.; Perpina, M. Duration of length of stay in pneumonia: Influence of clinical factors and hospital type. Eur. Respir. J. 2003, 22, 643-648. [CrossRef]

31. American Thoracic Society (ATS); Infectious Diseases Society of America (IDSA). Guidelines for the management of adults with hospital-acquired, ventilator-associated, and healthcareassociated pneumonia. Am. J. Respir. Crit. Care Med. 2005, 171, 388-416. [CrossRef] 
32. Carratala, J.; Mykietiuk, A.; Fernandez-Sabe, N.; Suarez, C.; Dorca, J.; Verdaguer, R.; Manresa, F.; Gudiol, F. Health care-associated pneumonia requiring hospital admission: Epidemiology, antibiotic therapy, and clinical outcomes. Arch. Intern. Med. 2007, 167, 1393-1399. [CrossRef]

33. Chalmers, J.D.; Taylor, J.K.; Singanayagam, A.; Fleming, G.B.; Akram, A.R.; Mandal, P.; Choudhury, G.; Hill, A.T. Epidemiology, antibiotic therapy, and clinical outcomes in health care-associated pneumonia: A UK cohort study. Clin. Infect. Dis. 2011, 53, 107-113. [CrossRef]

34. Garcia-Vidal, C.; Viasus, D.; Roset, A.; Adamuz, J.; Verdaguer, R.; Dorca, J.; Gudiol, F.; Carratala, J. Low incidence of multidrugresistant organisms in patients with healthcare-associated pneumonia requiring hospitalization. Clin. Microbiol. Infect. 2011, 17, 1659-1665. [CrossRef]

35. Ewig, S.; Welte, T. Adding fuel to the flames? It is time to leave HCAP. Respir. Med. 2012, 106, 1309-1310. [CrossRef]

36. Marshall, D.C.; Goodson, R.J.; Xu, Y.; Komorowski, M.; Shalhoub, J.; Maruthappu, M.; Salciccioli, J.D. Trends in mortality from pneumonia in the Europe union: A temporal analysis of the European detailed mortality database between 2001 and 2014 . Respir. Res. 2018, 19, 81. [CrossRef] [PubMed]

37. Direção-Geral da Saúde. Vacinação Contra Infeções por Streptococcus Pneumoniae de Grupos com Risco Acrescido para Doença Invasiva Pneumocócica (DIP)-Adultos ( $\geq 18$ anos de idade): Norma $n^{\circ}$ 011/2015, de 23/06/2015, Atualização de 06/11/2015; DGS: Lisboa, Portugal, 2015.

38. Froes, F.; Diniz, A.; Robalo Cordeiro, C.; Serrado, M.; Ramalho de Almeida, A.; Portuguese Respiratory, S. Consensus document for the prevention of respiratory infections in adults. Rev. Port. Pneumol. 2014, 20, 111-114. [CrossRef] [PubMed]

39. Despacho $n .^{\circ}$ 2902/2013 Programa de Prevenção e Controlo de Infeções e de Resistência aos Antimicrobianos (PPCIRA), pelo Despacho n. ${ }^{\circ}$ 2902/2013; Diário da República, 2. Série, n. ${ }^{\circ}$ 38; Imprensa Nacional Casa da Moeda: Lisboa, Portugal, 2013.

40. Hespanhol, V.; Barbara, C. Pneumonia mortality, comorbidities matter? Pulmonology 2020, 26, 123-129. [CrossRef]

41. Méndez, L.; Pedrosa, A.; Caneiras, C. Growing Growing importance of Gram-negative isolates in respiratory samples. Eur. Respir. J. 2020, 56, 2027. [CrossRef]

42. Zilberberg, M.D.; Shorr, A.F. Epidemiology of healthcare-associated pneumonia (HCAP). Semin. Respir. Crit. Care Med. 2009, 30, 10-15. [CrossRef] [PubMed]

43. Cattani, G.; Madia, A.; Arnoldo, L.; Brunelli, L.; Celotto, D.; Grillone, L.; Valent, F.; Castriotta, L.; Pea, F.; Bassetti, M.; et al. Assessment of the impact of clinical recommendations on antibiotic use for CAP and HCAP: Results from an implementation program in an Academic Hospital. Ann Ig 2020, 32, 344-356. [CrossRef]

44. Behnke, M.; Valik, J.K.; Gubbels, S.; Teixeira, D.; Kristensen, B.; Abbas, M.; van Rooden, S.M.; Gastmeier, P.; van Mourik, M.S.M.; Aspevall, O.; et al. Information technology aspects of large-scale implementation of automated surveillance of healthcareassociated infections. Clin. Microbiol. Infect. 2021, 27 (Suppl. 1), S29-S39. [CrossRef] [PubMed]

45. Duszynska, W.; Rosenthal, V.D.; Szczesny, A.; Zajaczkowska, K.; Fulek, M.; Tomaszewski, J. Device associated -health care associated infections monitoring, prevention and cost assessment at intensive care unit of University Hospital in Poland (2015-2017). BMC Infect. Dis. 2020, 20, 761. [CrossRef]

46. Hoskins, A.J.; Worth, L.J.; Imam, N.; Johnson, S.A.; Bull, A.L.; Richards, M.J.; Bennett, N.J. Validation of healthcare-associated infection surveillance in smaller Australian hospitals. J. Hosp. Infect. 2018, 99, 85-88. [CrossRef] [PubMed]

47. Magill, S.S.; Dumyati, G.; Ray, S.M.; Fridkin, S.K. Evaluating Epidemiology and Improving Surveillance of Infections Associated with Health Care, United States. Emerg. Infect. Dis. 2015, 21, 1537-1542. [CrossRef]

48. Migliara, G.; Di Paolo, C.; Barbato, D.; Baccolini, V.; Salerno, C.; Nardi, A.; Alessandri, F.; Giordano, A.; Tufi, D.; Marinelli, L.; et al. Multimodal surveillance of healthcare associated infections in an intensive care unit of a large teaching hospital. Ann Ig 2019, 31, 399-413. [CrossRef]

49. Metlay, J.P.; Waterer, G.W.; Long, A.C.; Anzueto, A.; Brozek, J.; Crothers, K.; Cooley, L.A.; Dean, N.C.; Fine, M.J.; Flanders, S.A.; et al. Diagnosis and Treatment of Adults with Community-acquired Pneumonia. An Official Clinical Practice Guideline of the American Thoracic Society and Infectious Diseases Society of America. Am. J. Respir. Crit. Care Med. 2019, 200 , e45-e67. [CrossRef] [PubMed] 